\title{
Dipyrone, isometheptene and caffeine association in mild to moderate primary headache: a randomized comparative double-blind study with paracetamol and placebo
}

\author{
Uso da associação de dipirona, isometepteno e cafeína na cefaleia primária leve a moderada: \\ estudo randomizado, cruzado e duplo-cego comparativo com paracetamol e placebo
}

\author{
Pedro André Kowacs ${ }^{\circledR 1}$, Fabiana Roveda ${ }^{\circledR 2}$, Nívia Jardim Tosetto ${ }^{\circledR 2}$, Deusvenir de Souza Carvalho ${ }^{\circledR 3}$
}

\begin{abstract}
Objectives: The present study aims to evaluate the efficacy, tolerability and compliance of a fixed combination of dipyrone, isometheptene and caffeine versus paracetamol and placebo for the treatment of acute primary headache disorders. Method: A phase IV, multicentric, double-blind, placebo-controlled, randomized, crossover, prospective study was conducted. Approximately equal number of patients received dipyrone $300 \mathrm{mg}$, isometheptene $50 \mathrm{mg}$ and caffeine $30 \mathrm{mg}$ (combination therapy), paracetamol $200 \mathrm{mg} / \mathrm{ml}$ or placebo (oral drops). The primary efficacy endpoint was sustained pain-free (SPF) rate, defined as being headache-free at 120 minutes, without recurrences of any intensity or the use of rescue medication within 24 hours of treatment. Results: Among 99 subjects, most of them classified as having mild to moderate headache $(96.0 \%)$, primary endpoint was achieved by $61.8 \%, 48.7 \%$ and $28.9 \%$ treated with combined therapy, paracetamol and placebo, respectively. A significative improvement in pain severity was observed with combined therapy at 30 and 90 minutes and in headache-related interference on daily activities after 30 minutes versus paracetamol.
\end{abstract}

1. Head of the Neurology Service and of the Clinical Research Unit of the Neurological Institute of Curitiba, and Coordinator of the Headache and Pain Unit of the Neurology Service of the Clinics Hospital, Brazilian Federal University at Paraná. Founding member of the Avidas Institute Curitiba - PR - Brasil

2. Medical Manager at Takeda Company. São Paulo-SP-Brasil

3. Retired Associated Professor and ex-Head of the Headaches Investigation and Treatment Sector of the Neurology Discipline, Department of Clinical Neurology and Neurosurgery of Universidade Federal de São Paulo. São Paulo - SP - Brasil

Institution: Takeda Company. São Paulo-Brasil

Correspondence address: Deusvenir de Souza Carvalho. Rua Pedro de Toledo, 980 conj 33, Vila Mariana - 04039-002 - São Paulo-SP - Brasil.E-mail:deusveni@gmail.com

Financial support: This study was funded by Takeda

No conflicts of interest
Both active treatments showed grater satisfaction levels versus placebo after 24 hours. No serious adverse events were registered. Conclusions: Substantial therapeutic gain was obtained with combined therapy on patients with mild to moderate acute primary headache episodes versus paracetamol and placebo. A favorable and tolerable safety profile was reported.

Keywords: Headache disorders, primary; Dipyrone; Isometheptene; Caffeine; Acetaminophen; Clinical trial

\section{Resumo}

Fundamento: A associação de dipirona, isometepteno e cafeína tem sido utilizada no Brasil para o tratamento de cefaleias primárias agudas. Objetivo: O estudo teve como objetivo avaliar a eficácia, tolerabilidade e adesão de uma combinação fixa de dipirona, isometepteno e cafeina, em comparação com paracetamol e placebo, para o tratamento de cefaleias primárias agudas. Métodos: Foi realizado um estudo prospectivo, multicêntrico, randomizado, duplo-cego, cruzado, controlado por placebo e de fase IV. Um número aproximadamente igual de pacientes recebeu a combinação de dipirona $300 \mathrm{mg}$, isometepteno $50 \mathrm{mg}$ e cafeina $30 \mathrm{mg}$ (terapia combinada), paracetamol $200 \mathrm{mg} / \mathrm{ml}$ ou placebo (solução oral). O desfecho primário de eficácia consistiu na proporção de pacientes com ausência total da dor após 120 minutos, sem reincidências ou uso de medicamento de resgate por 24 horas. Resultados: Entre 99 pacientes, $o$ desfecho primário foi alcançado por $61,8 \%, 48,7 \%$ e 28,9\% dos pacientes tratados com terapia combinada, paracetamol e placebo, respectivamente. Melhora significativa foi observada na gravidade da dor com a terapia combinada em 30 e 90 minutos e na interferência da cefaleia nas atividades diárias após 30 minutos versus paracetamol. Ambos os tratamentos ativos apresentaram maiores níveis de satisfação versus placebo, após 24 horas. Nenhum evento adverso grave foi relatado. Conclusão: Obteve-se um ganho terapêutico substancial com a terapia combinada, em pacientes com episódios de cefaleia primária aguda leve a moderada versus 
paracetamol e placebo. Um perfil de segurança favorável e tolerável foi reportado.

Descritores: Transtornos da cefaleia primários, Dipirona, Isometepteno, Cafeina, Acetaminofen, Ensaio clínico

\section{Introduction}

Headache constitutes one of the main presentation of nervous system primary and secondary disorders ${ }^{(1)}$. If these conditions are not associated with a clear cause, as a pathology, trauma, or systemic disease, they are named primary headache disorders ${ }^{(2)}$, which constitute the majority of headache cases $^{(1)}$. According to the International Classification of Headache Disorders, primary headache disorders can be classified as migraine, tension-type headache (TTH), trigeminal autonomic cephalalgias (as cluster headache, depending on the edition) and other primary headache disorders ${ }^{(3-4)}$. While migraine's burden is of public health importance, the usually less intense tension-type headache and the more intense but less frequent trigeminal autonomic cephalalgias undoubtedly diminish patients' quality of life ${ }^{(5-6)}$. Additionally, these disorders can also be classified as episodic (frequent or infrequent) or chronic according to the number of days with headache episodes experienced by a person ${ }^{(7)}$.

Globally, the most prevalent type of headache disorder is TTH $(60-80 \%)$, followed by migraine $(15 \%)$ (5). In Brazil, the mean 1-year prevalence of headache is $70.6 \%$ (29.5\% for TTH and $15.8 \%$ for migraine cases), occurring most frequently among women ${ }^{(8)}$. TTH is usually associated to emotional and physical stress ${ }^{(9)}$ and it is characterized by the presence of at least two of the following features: bilateral pain location, pressing quality non-pulsating, mild to moderate intensity and no aggravation related to day-by-day activities such as walking and climbing stairs ${ }^{(7)}$.

Headache disorders are among the 10 main causes of disability around the world and its impact is considered similar to arthritis and diabetes ${ }^{(10)}$. Headache disorders are associated with quality of life impairment and economic burden, since it frequently affects routine activities and work productivity, mainly in individuals experiencing frequent episodes ${ }^{(11)}$.

The treatment of headache disorders demands the existence of qualified health professionals, an accurate diagnosis and patient education associated with adequacy in lifestyle ${ }^{(1)}$. Usually antimigraine medications are taken by patients without a prescription ${ }^{(12)}$. According to a Brazilian guideline, TTH treatment could be conducted with analgesics and non-hormonal anti-inflammatories. Moreover, tricyclic antidepressants (amitriptyline) could be beneficial in TTH prevention. In case of mild to moderate migraine, dipyrone, acetyl- salicylic acid and non-hormonal anti-inflammatories are considered acceptable treatment options by Brazilian guideline. For patients with mild to moderate migraine who present lack of response to these medications, the use of isometheptene with an analgesic (dipyrone, paracetamol or acetylsalicylic acid) or the association of this product with caffeine and analgesics are recommended. Also, patients with moderate migraine may require the use of triptans. Additionally, triptans can also be used for the treatment of frequent headache attacks, as well as ergotamine ${ }^{(13)}$.

However, some barriers to an effective access to treatment of headache disorders are identified. Currently, only $40 \%$ of individuals with headache disorders are diagnosed by health-care professionals and are properly treated ${ }^{(1)}$. Also, clinical features of headache disorders vary widely regarding frequency of attacks (episodic or chronic cases) and symptomatology, as for severity and duration of episodes. Therefore, these features associated with the lack of disease biological markers limit headache disorders treatment to empirical strategies ${ }^{(14)}$. Additionally, the lack of health-care providers knowledge and poor awareness on the substantial burden of headache disorders for society by the general population and governments contributes to aggravate this scenario ${ }^{(1)}$.

The association of dipyrone with isometheptene and caffeine has been used in Brazil for the treatment of several acute primary headache disorders. However, the scientific literature about this approach is scarce, probably due to the limitations previously described. Dipyrone is a non-opioid agent with analgesic, spasmolytic and antipyretic properties, with multiple mechanisms of action ${ }^{(15)}$; isometheptene mucate is a sympathomimetic amine that presents vasoconstricting and analgesic properties, primarily related to alpha-adrenoceptors ${ }^{(16)}$; and caffeine is a methylxanthine and a central nervous system stimulant through the blockade of adenosine depressing effects, contributing to pain relief ${ }^{(17)}$.

The present study aims to evaluate the efficacy, tolerability and compliance of a fixed combination of dipyrone $(300 \mathrm{mg})$, isometheptene $(50 \mathrm{mg})$ and caffeine (30 mg) taken as oral drops, as compared to placebo oral drops and to paracetamol $(200 \mathrm{mg} / \mathrm{ml})$ oral drops, for the treatment of acute primary headache disorders, diagnosed according to $2^{\text {nd }}$ edition of The International Classification of Headache Disorders (ICHD-2) criteria of the International Headache Society.

\section{Patients and Methods}

This was a phase IV, multicentric, double-blind, placebo-controlled, randomized, crossover, prospective study, comparing the efficacy and tolerability 
of combined dipyrone, isometheptene and caffeine versus paracetamol and placebo. Inclusion criteria were both genders, age between 18 and 65 years, under outpatient follow-up and treatment, with diagnosis of primary headache with gradual onset and frequency lower than 15 days per month (ICHD2), normal or controlled blood pressure (systolic blood pressure $<140 \mathrm{mmHg}$ and diastolic blood pressure $<90 \mathrm{mmHg}$ ), using a contraceptive method, with conditions to understand and maintain the treatment and able to provide an informed consent. Patients were excluded from the study if one of the following characteristics were observed: participation in a clinical trial in a 30-day period before the first study visit; hospitalization or need for emergency care; chronic (greater than 15 days per month) or secondary headache; a medication overuse history; chronic use or using corticosteroids, non-steroidal anti-inflammatory drugs, lithium, carbamazepine, chlorpromazine, cyclosporine, tranquilizers, triptans, anticoagulants, nitrates; hypersensitivity to components of active product or non-steroidal anti-inflammatory drugs; changes in blood count and liver enzymes; clinical history of asthma, hydropeptic, renal, hepatic and/or hematopoietic disorders; concomitant severe systemic diseases; current history of illicit drug use or alcohol abuse; unable to successfully adhere to treatment; intending to become pregnant during the study period or with suspected or confirmed pregnancy or lactating women; other conditions defined by medical discretion. The study was conducted from September, 2007 until January, 2008 in five study centers located on Brazil's south and southeast regions (C1: UNIFESP SITC - Setor de Investigacao e Tratamento das Cefaleias; C2: Irmandade Santa Casa de Misericordia de Porto Alegre; C3: Universidade Metodista de Santos - UNIMES; C4: Irmandade Santa Casa de Misericordia de Sao Paulo; C5: Instituto de Neurologia de Curitiba Hospital Ecoville).

The study comprised the treatment of three consecutive headache episodes over a maximum period of 6 weeks. Each episode was treated with one of the study medications or placebo in a randomized sequence, according to the crossover design. Eligible episodes had to be separated at least by a 24-hour pain-free interval. Study duration was three headache episodes or six weeks (whichever occurred first).

Combination therapy was administered as oral drops (each $1 \mathrm{~mL}$ contains dipyrone $300 \mathrm{mg}$, isometheptene $50 \mathrm{mg}$ and caffeine $30 \mathrm{mg}$ ). Paracetamol was administered as oral drops (each $1 \mathrm{~mL}$ contains paracetamol $200 \mathrm{mg}$ ), as generic medication, and was selected as the active comparator since it is the third medication most used to treat headache episodes in Brazil, after dipyrone and dipyrone compounds ${ }^{(18)}$. Placebo vials were identical to medication vials, in order to maintain patients' blindness. Allocation was defined using sequentially numbered labels and professionals were unaware of the relationship between the number and treatment provided. Headache episodes were treated according to the medication's leaflefts. Patients were allowed to the use of a rescue medication (ibuprofen $400 \mathrm{mg}$ ) if mild headache persisted or aggravated after two hours of the trial medication intake (therapeutic failure).

Patients were assessed at the baseline and after three headache episodes or six weeks (whichever occurred first). During the baseline visit, subjects were instructed regarding trial procedures and received a diary to register headache events and medication use. Pain severity was graded using a 10-point visual analog scale (VAS) ${ }^{(19)}$, as well as, by a 4-point categorical scale (where no pain $=0$; severe pain $=3$ ). Interference of pain on daily activities was assessed using a 4-point scale (no interference $=0$; incapacity $=$ 3). These assessments were conducted at the baseline visit (previous episodes), at the onset of each headache episode and then at 30, 60, 90, 120 and $240 \mathrm{~min}$ after treatment intake. Associated symptoms were assessed at the same time points. Study centers were trained before procedures initiation in order to standardize data collection.

The primary efficacy endpoint was sustained painfree $(\mathrm{SPF})$ rate. SPF was defined as being headache-free at 120 minutes, without recurrences of any intensity or the use of rescue medication within 24 hours of treatment. Recurrence was defined as the presence of pain of any severity, following total pain relief, within 24 hours of drug intake. Secondary endpoints were: pain intensity and its variation compared to baseline at different time points; headache interference on daily activities; assessment of associated symptoms as function of treatment and time after treatment, sustained efficacy for 24 hours, considering recurrence, time to recurrence and rescue medication use and patient satisfaction with the used treatment.

Also, safety and compliance to treatment analysis were performed. Safety analysis was performed with patients in the intention to treat (ITT) population with at least one safety assessment after starting treatment. Compliance to treatment was analyzed by verifying the return of the vials by patients after the treatment period. This verification was performed at visit 2 and was recorded in the patient's clinical record. Compliance was defined as the intake of the study drug vial in each headache attack.

Sample size was calculated based on the primary endpoint, considering a significance level of $5 \%$ and statistical power of $90 \%$. Primary endpoint was evaluated through McNemar's test. Considering that a response rate of $25 \%$ for placebo and $60 \%$ for the 
association was expected, a sample of 69 evaluable patients were required to detect a $35 \%$ difference between study groups.

Data were analyzed initially through descriptive analysis, using measures of central tendency and dispersion and measures of frequency. Primary endpoint was assessed using McNemar's test and linear models. Secondary endpoints were assessed using methods such as Cochran-Mantel-Haenszel test, Fisher exact test and Kaplan-Meier, depending on the characteristics of the variables.

The study was performed in accordance with the guidelines of the International Headache Society and Brazilian Society of Headache, the Declaration of Helsinki and the Brazilian National Health Institution regulations (Rio de Janeiro, Brazil). The protocol ( $\left.{ }^{\circ} 144 / 07\right)$ was approved by Institutional Ethics Committee of participating centers and by the National Research Ethics Committee and met the standards of Good Clinical Practice guidelines. All subjects gave written informed consent before enrolment in the study. In compliance with the regulatory standards at the time, this study was not registered on the Brazilian Clinical Trials Registry due to the period of its clinical activity (2007-2008) occurring before the legislation - RDC no 36 of June 27th, 2012 - that mandated this kind of submission ${ }^{(20)}$

\section{Results}

The study was conducted in five centers with a total of 118 individuals $(\mathrm{C} 1: 25 ; \mathrm{C} 2: 19 ; \mathrm{C} 3: 49$; C4: 10; C5: 15) assessed for eligibility (Figure 1). The ITT population to assess efficacy (ITTe) consisted of 99 subjects, 12 were excluded due to lack of headache episodes, while seven presented less than two episodes. The ITT population to assess safety (ITTs) included all patients from the ITT population $(n=106)$.

Sociodemographic and headache characteristics of the studied sample are shown in (Table 1).The ITT population is composed mostly by women $(89 \%)$ with mean age of $33.9 \pm 11.4$ years (median: 31 years; ranging from 18 to 65 years).

Mean diastolic blood pressure, systolic blood pressure, and heart rate were $73.2 \pm 8.1 \mathrm{mmHg}, 115.2 \pm 11.4$ $\mathrm{mmHg}$, and $76.4 \pm 7.1 \mathrm{bpm}$, respectively. At baseline, patients reported a mean of $4.3 \pm 2.0$ days (median: 4 days; range: 2-14 days) of headache per month with mean headache duration of $890.0 \pm 867.3$ minutes (median: 720 minutes; range: 30-4320 minutes). Mean headache severity was $49.0 \pm 17.0 \mathrm{~mm}$ (median: $48 \mathrm{~mm}$; range: 8-100 $\mathrm{mm}$ ). The main type of headache was migraine without aura $(67 \%)$, followed by tensional headache $(9.4 \%)$ and other primary headache not classified elsewhere (9.4\%). Most patients reported mild headache $(81 \%)$ with only four reporting severe pain.

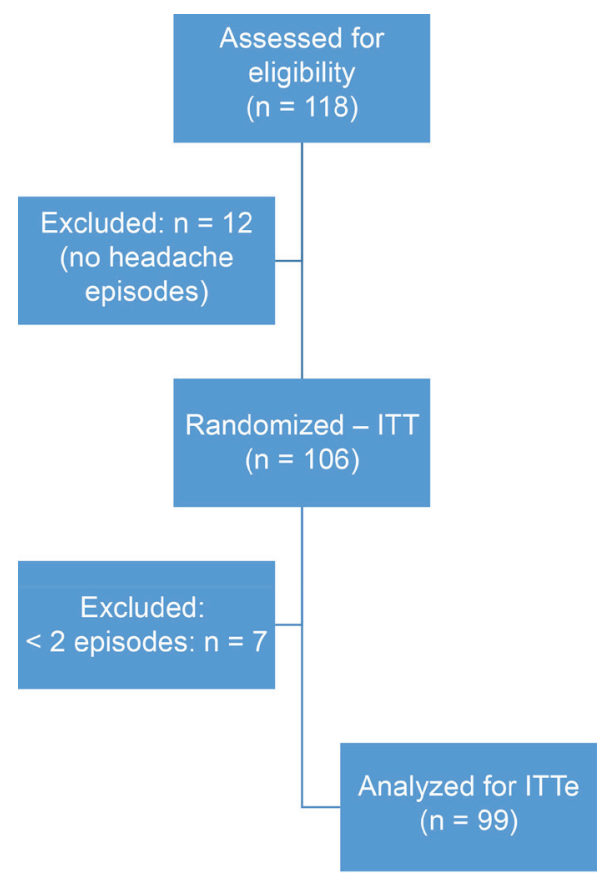

Figure 1. Trial profile. Headache disorders classified according to 2nd edition of The International Classification of Headache Disorders (ICHD-2).

Photophobia (74.5\%) and phonophobia (67\%) were the main associated symptoms.

In the ITTe population, primary endpoint was achieved by $61.8 \%, 48.7 \%$ and $28.9 \%$ of subjects treated with combination therapy, paracetamol and placebo, respectively. Treatment success was considered statistically significant for combination therapy versus placebo ( $p<0.01$ ), but statistical significance was not achieved for combination therapy versus paracetamol $(\mathrm{p}=0.086)$. Pain intensity (assessed using the VAS) is shown in (Figure 2). A comparison of headache severity, using the arithmetical differences in pain severity (before and after treatment) is presented in (Figure 3). The combination therapy reached statistically significant improvement in pain severity in all time points when compared to placebo ( $\mathrm{p}=0.0015,0.0001,<0.0001$ and $<0.0001$ at 30, 60, 90 and 120 minutes after treatment, respectively), but only marginal significance when compared to paracetamol $(\mathrm{p}=0.0419,0.0506$, 0.0349 and 0.0897 at $30,60,90$ and 120 minutes after treatment, respectively).

Headache-related interference on daily activities at the various time points after treatment is shown in (Table 2). Combination therapy showed statistically significant differences when compared to paracetamol $(\mathrm{p}=0.0209)$ and placebo $(\mathrm{p}=0.0321)$ on the first 30 minutes after treatment, showing evidences of faster action than the comparator.

Both active treatments showed higher levels of satisfaction compared to placebo. Combination treat- 


\section{Sociodemographic and headache characteristics of the studied sample.}

\begin{tabular}{|c|c|}
\hline Variables & $n(\%)$ \\
\hline $\begin{array}{l}\text { Gender } \\
\text { Male } \\
\text { Female }\end{array}$ & $\begin{array}{l}12(11.3) \\
94(88.7)\end{array}$ \\
\hline $\begin{array}{l}\text { Age } \\
18-30 \text { years old } \\
31-45 \text { years old } \\
46-60 \text { years old } \\
>60 \text { years old } \\
\text { Mean }(\mathrm{SD})\end{array}$ & $\begin{array}{c}52(49.1) \\
36(34.0) \\
16(15.1) \\
2(1.9) \\
33.9(11.4)\end{array}$ \\
\hline $\begin{array}{l}\text { Diagnosis/Headache classification } \\
\text { Migraine without aura } \\
\text { Migraine with typical aura and migranous headache } \\
\text { Migraine with typical aura and non-migranous headache } \\
\text { Probable migraine without aura } \\
\text { Probable migraine with aura } \\
\text { Associated with pericranial pain } \\
\text { Not associated with pericranial pain } \\
\text { Probable frequent tension-type headache } \\
\text { Headache, not elsewhere classified }\end{array}$ & $\begin{array}{c}71(67.0) \\
4(3.8) \\
1(0.9) \\
3(2.8) \\
1(0.9) \\
3(2.8) \\
10(9.4) \\
10(9.4) \\
3(2.8)\end{array}$ \\
\hline Days with headache - days (Mean [SD]) & $4.3(2.0)$ \\
\hline Headache duration - minutes (Mean [SD]) & $890.0(867.3)$ \\
\hline $\begin{array}{l}\text { Headache intensity } \\
\text { Mild } \\
\text { Moderate } \\
\text { Severe } \\
\text { VAS (Mean [SD]) }\end{array}$ & $\begin{array}{c}15(15.0) \\
81(81.0) \\
4(4.0) \\
49.0(17.0)\end{array}$ \\
\hline $\begin{array}{l}\text { Interference of headaches on daily activities* } \\
\text { No interference } \\
\text { Interference } \\
\text { Incapacity/great difficulty }\end{array}$ & $\begin{array}{c}22(21.0) \\
76(72.4) \\
7(6.7)\end{array}$ \\
\hline
\end{tabular}

*One patient with missing data. SD: Standard deviation. Headache disorders classified according to 2nd edition of The International Classification of Headache Disorders (ICHD-2).

ment was considered a better therapy when compared to usual care by 27 patients $(30.7 \%)$, paracetamol $(15.7 \%)$ and placebo $(13.6 \%)$. Those differences were considered statistically significant versus paracetamol $(\mathrm{p}=0.007)$ and placebo $(\mathrm{p}<0.0001)$.

The number of patients using rescue medication was significantly lower in those receiving combination therapy (19 patients, $20.7 \%$ ), paracetamol (30 patients; $33.3 \%, \mathrm{p}=0.054$ ) and placebo (52 patients; $56.5 \%, \mathrm{p}<$ 0.0001 ). (Figure 4) displays the Kaplan-Meier analysis for the time from treatment to rescue medication use. Three patients $(3.3 \%)$ treated with the combination therapy required rescue treatment, while $8(8.9 \%$; $p=$ $0.131)$ and $16(17.5 \% ; \mathrm{p}=0.001)$ made use of it while treated with paracetamol and placebo, respectively.

Twenty-three episodes of adverse events were reported in $13(13.1 \%)$ patients. Fourteen episodes were considered as little or probably related to the proposed intervention, which occurred in nine patients $(9.1 \%)$.
Adverse events probably related to the intervention were: somnolence; upper abdominal pain; dizziness; vomiting; erythema; and nausea. Regarding intensity, $20(86.96 \%)$ were considered mild , one $(4.35 \%)$ moderate and two $(8.70 \%)$ of severe intensity. All patients recovered from adverse events without sequelae. Only three gastrointestinal (two nausea cases and one vomiting case) adverse events were reported in two patients $(2.0 \%)$, all of them of mild intensity. No serious adverse events were registered, and all events were transient and resolved fully without further therapy. No changes from baseline in physical examination or laboratory tests were observed. Compliance to treatment in the ITT population was $95 \%$.

\section{Discussion}

To date, treatment for mild to moderate acute primary headache crises is limited, mainly due to the 


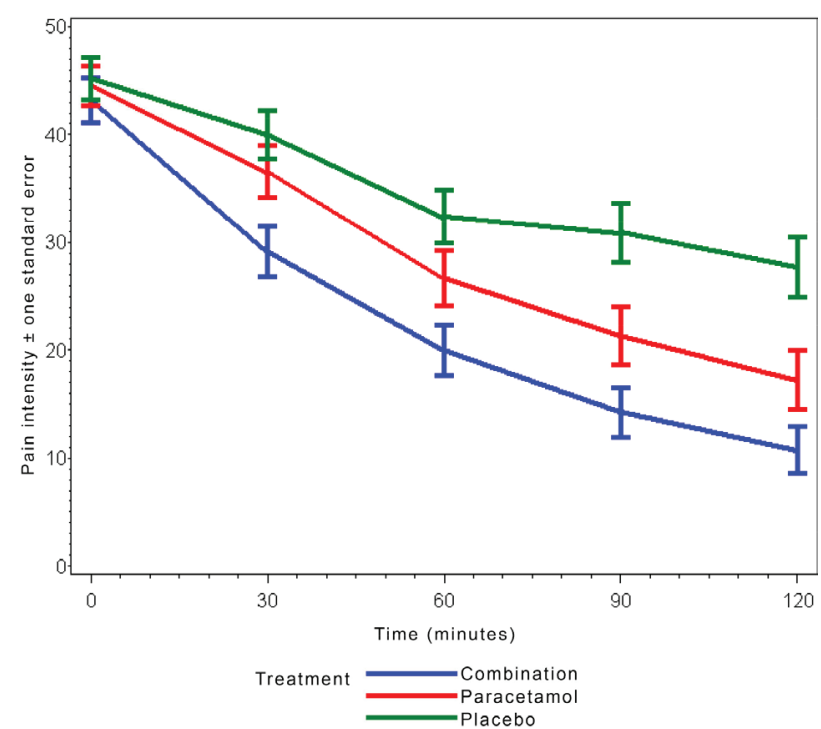

Figure 2. Evolution of pain severity assessed through visual analog scale. Combination therapy: oral drops (each $1 \mathrm{~mL}$ contains dipyrone $300 \mathrm{mg}$, isometheptene $50 \mathrm{mg}$ and caffeine $30 \mathrm{mg}$ ). Paracetamol: oral drops (each $1 \mathrm{~mL}$ contains paracetamol $200 \mathrm{mg}$ ).

difficulties in seeking professional guidance by patients. Most subjects underestimate the disease burden and practice self-medication, pursuing appropriate treatment only after symptoms intensification ${ }^{(12,14)}$. From 2013 to 2014, the prevalence of self-medication in Brazil was $16.1 \%$, primarily of analgesics (dipyrone) ${ }^{(21)}$. The lack of clinical evidence on efficacy and safety of over-the-counter medications is common for some indications. This fact contributes to the challenging practice of evidence-based recommendations for the treatment of mild to moderate acute primary headache attacks ${ }^{(14)}$.

In the present study, dipyrone combination with isometheptene and caffeine (oral drops) showed substantial therapeutic gain versus paracetamol and placebo. The association was considered more successful than placebo and provided a significative greater SPF rate and improvement in pain severity in the first two hours after the treatment (including photophobia and phonophobia). There was also a significative improvement in pain severity by combination therapy compared to paracetamol at 30 and 90 minutes after treatment.

Additionally, combination therapy improved significantly headache-related interference on daily activities compared to placebo and paracetamol and, therefore, provided benefits to patients' health-related quality of life. Moreover, combination therapy showed higher levels of satisfaction among patients versus placebo and paracetamol and required significative lower use of rescue therapy than the comparators, after 24 hours. Compliance rates were also elevated in study population.

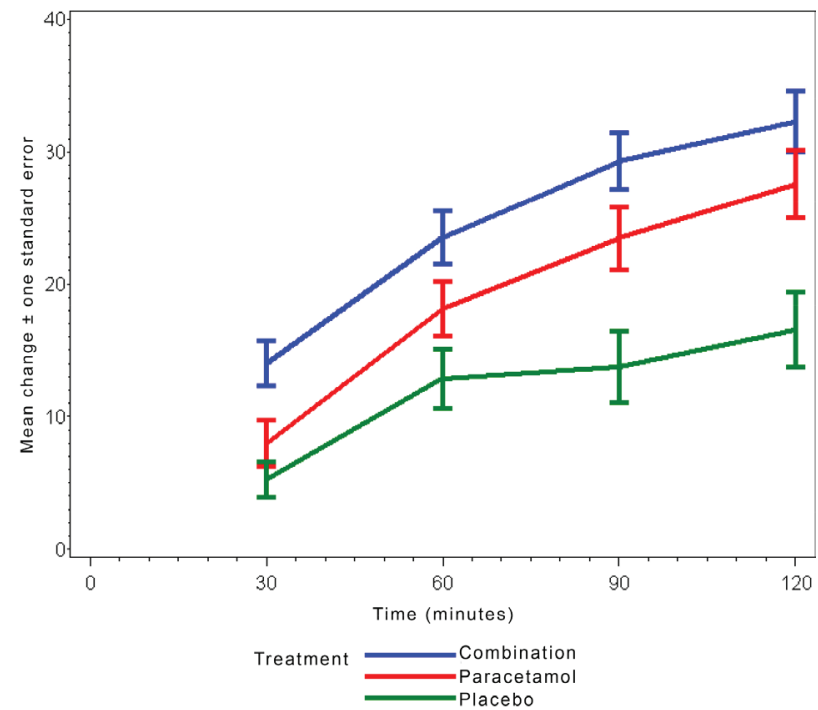

Figure 3. Pain severity score reduction after treatment. Combination therapy: oral drops (each $1 \mathrm{~mL}$ contains dipyrone $300 \mathrm{mg}$, isometheptene $50 \mathrm{mg}$ and caffeine $30 \mathrm{mg}$ ). Paracetamol: oral drops (each $1 \mathrm{~mL}$ contains paracetamol 200 $\mathrm{mg}$ ). Severity score was calculated through a visual analogue scale or 4-point categorical scale.

Combination therapy presented significative results after 30 minutes when compared to paracetamol, representing a faster action onset. These results are relevant, since evidence have shown that, despite the existence of effective acute treatments for migraine, the majority of individuals prefers therapeutic options providing rapid onset of complete pain relief $f^{(22)}$.

Former evidence has shown that monotherapeutic approaches with analgesics results in suboptimal relief of attack symptoms in patients with migraine. Furthermore, polytherapy, by acting on more than one system associated with headache pathophysiology may explain why this approach is more efficacious than targeting a single mechanism ${ }^{(22)}$. According to a Brazilian guideline, patients with mild to moderate migraine and lack of response to monotherapy medication can be treated with an isometheptene associated to caffeine and an analgesic (dipyrone, for example), though triptans may be required for moderate migraine cases $^{(13)}$. In spite of triptans relevance, they are still not considered necessarily the best treatment option in this population ${ }^{(22)}$. High prevalence of gastrointestinal adverse events has been reported for patients treated with triptans, such as gastroparesis, nausea and vomiting. These adverse events present a high impact in patient's quality of life and are considered one of the greatest challenges regarding migraine treatment ${ }^{(23)}$. In this scenario, the current study reported a low incidence of gastrointestinal adverse events in the iTTs population of patients with mild to moderate primary headache, mainly migraine $(67 \%)$. All these 
Table 2

\begin{tabular}{|c|c|c|c|c|c|c|c|c|c|c|}
\hline \multirow{3}{*}{$\begin{array}{l}\text { Time } \\
\text { (min) }\end{array}$} & \multicolumn{9}{|c|}{ Interference } & \multirow{3}{*}{$p$-value } \\
\hline & \multirow[t]{2}{*}{ Treatments } & \multicolumn{2}{|c|}{ No interference } & \multicolumn{2}{|c|}{ Interference } & \multicolumn{2}{|c|}{$\begin{array}{l}\text { Incapacity/ } \\
\text { great difficulty }\end{array}$} & \multicolumn{2}{|c|}{$\begin{array}{l}\text { Incapacity/ } \\
\text { unknown cause }\end{array}$} & \\
\hline & & $\mathrm{N}$ & $\%$ & $\mathrm{n}$ & $\%$ & $\mathrm{n}$ & $\%$ & $\mathrm{n}$ & $\%$ & \\
\hline \multirow[t]{2}{*}{30} & Combination & 43 & 58.9 & 27 & 37.0 & 3 & 4.1 & - & - & $0.0321^{*}$ \\
\hline & Placebo & 29 & 39.7 & 41 & 56.2 & 2 & 2.7 & 1 & 1.4 & \\
\hline \multirow[t]{2}{*}{60} & Combination & 39 & 67.2 & 17 & 29.3 & 2 & 3.4 & - & - & 0.0555 \\
\hline & Placebo & 29 & 50.0 & 26 & 44.8 & 3 & 5.2 & - & - & \\
\hline \multirow[t]{2}{*}{90} & Combination & 26 & 65.0 & 12 & 30.0 & 1 & 2.5 & 1 & 2.5 & 0.2393 \\
\hline & Placebo & 18 & 45.0 & 21 & 52.5 & 1 & 2.5 & - & - & \\
\hline \multirow[t]{2}{*}{120} & Combination & 22 & 66.7 & 8 & 24.2 & 2 & 6.1 & 1 & 3.0 & 0.3531 \\
\hline & Placebo & 15 & 45.5 & 16 & 48.5 & 2 & 6.1 & - & - & \\
\hline \multirow[t]{2}{*}{30} & Combination & 44 & 63.8 & 22 & 31.9 & 3 & 4.3 & - & - & $0.0209^{*}$ \\
\hline & Paracetamol & 30 & 43.5 & 35 & 50.7 & 3 & 4.3 & 1 & 1.4 & \\
\hline \multirow[t]{2}{*}{60} & Combination & 35 & 64.8 & 17 & 31.5 & 2 & 3.7 & - & - & 0.8272 \\
\hline & Paracetamol & 32 & 59.3 & 22 & 40.7 & - & - & - & - & \\
\hline \multirow[t]{2}{*}{90} & Combination & 21 & 65.6 & 9 & 28.1 & 1 & 3.1 & 1 & 3.1 & 1.000 \\
\hline & Paracetamol & 18 & 56.3 & 14 & 43.8 & - & - & - & - & \\
\hline \multirow[t]{2}{*}{120} & Combination & 16 & 66.7 & 5 & 20.8 & 2 & 8.3 & 1 & 4.2 & 0.1444 \\
\hline & Paracetamol & 19 & 79.2 & 5 & 20.8 & - & - & - & - & \\
\hline \multirow[t]{2}{*}{30} & Placebo & 28 & 37.8 & 42 & 56.8 & 3 & 4.1 & 1 & 1.4 & 0.5464 \\
\hline & Paracetamol & 32 & 43.2 & 38 & 51.4 & 3 & 4.1 & 1 & 1.4 & \\
\hline \multirow[t]{2}{*}{60} & Placebo & 31 & 50.0 & 28 & 45.2 & 3 & 4.8 & - & - & 0.2393 \\
\hline & Paracetamol & 35 & 56.5 & 26 & 41.9 & 1 & 1.6 & - & - & \\
\hline \multirow[t]{2}{*}{90} & Placebo & 19 & 42.2 & 24 & 53.3 & 2 & 4.4 & - & - & 0.0736 \\
\hline & Paracetamol & 25 & 55.6 & 20 & 44.4 & - & - & - & - & \\
\hline \multirow[t]{2}{*}{120} & Placebo & 16 & 43.2 & 18 & 48.6 & 3 & 8.1 & - & - & $0.0027^{*}$ \\
\hline & Paracetamol & 25 & 67.6 & 12 & 32.4 & - & - & - & - & \\
\hline
\end{tabular}

*Statistically significant. Combination therapy: oral drops (each $1 \mathrm{~mL}$ contains dipyrone $300 \mathrm{mg}$, isometheptene $50 \mathrm{mg}$ and caffeine $30 \mathrm{mg}$ ). Paracetamol: oral drops (each $1 \mathrm{~mL}$ contains paracetamol $200 \mathrm{mg}$ ). Interference assessed using a 4-point scale.

adverse events were of mild intensity, a finding that could probably contribute to a decision towards using the combined drug for mild to moderate primary headaches attacks treatment, among available options.

These clinical trial results also demonstrated a favorable safety profile and tolerability of dipyrone, isometheptene and caffeine association. In contrast, intolerance to ergotamine, another drug recommended by a Brazilian guideline for acute headache attacks treatment, is usually high due to elevated frequency of adverse events commonly reported, primarily nausea and vomiting ${ }^{(24)}$.

The current study presents some strengths. The study design represents high level of evidence and sample size was more than sufficient to provide a power of $90 \%$ and contribute to robustness of results. The use of paracetamol as active comparator enables a comparison between current available treatment alternative for the treatment of primary headache disorders in Brazil. Moreover, placebo as comparator is relevant in headache trials, since it relieves around $43 \%$ of headache episodes in clinical trials scenarios and subsidize a greater evaluation of study active comparators ${ }^{(25)}$. However, some limitations are presented. Since the study included only patients that experienced mild to moderate headache episodes, outcome results may be overestimated. Another limitation is the inclusion of patients based on an outdated disease classification, since ICHD-2 was the version available at the time of study protocol design. However, main categories of pri- 


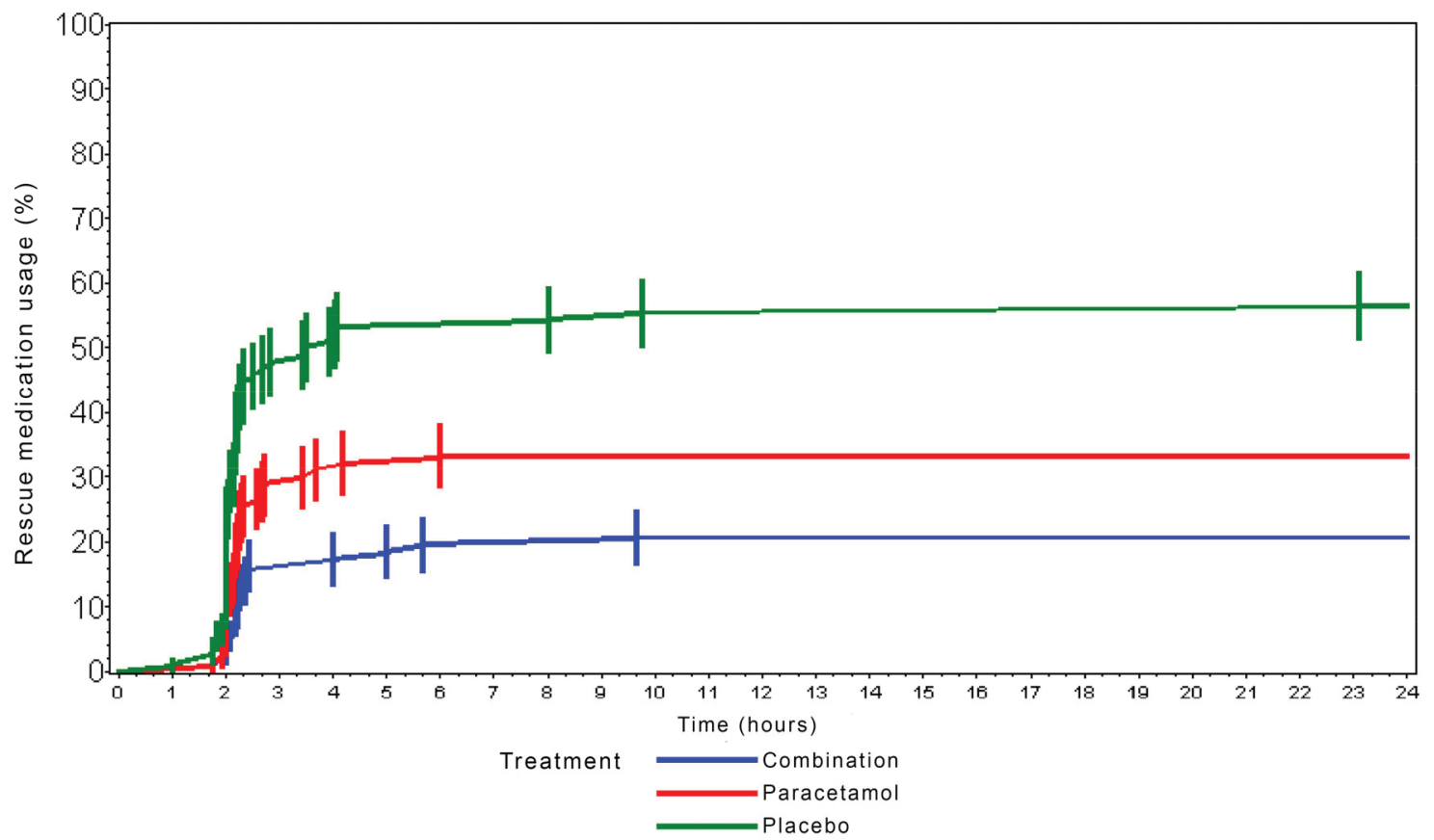

Figure 4. Proportion of patients using rescue medication over $24 \mathrm{~h}$. Combination therapy: oral drops (each $1 \mathrm{~mL}$ contains dipyrone $300 \mathrm{mg}$, isometheptene $50 \mathrm{mg}$ and caffeine $30 \mathrm{mg}$ ). Paracetamol: oral drops (each $1 \mathrm{~mL}$ contains paracetamol $200 \mathrm{mg}$ ). Rescue medication: ibuprofen $400 \mathrm{mg}$.

mary headache disorders remain classified as migraine, tension-type headache (TTH), trigeminal autonomic cephalalgias and other primary headache disorders, in exception of cluster headaches that are now a subcategory of trigeminal autonomic cephalalgias, in the $3^{\text {rd }}$ edition of the International Classification of Headache Disorders ${ }^{(3,4)}$. Although the use of drugs that could interfere with study medication was defined as exclusion criteria, a wash-out period was not defined and may also compromise study results. Finally, despite this is a multicenter study, only south and southeast regions from Brazil were represented in the included sample.

\section{Conclusions}

Substantial therapeutic gain was obtained with combined therapy treatment for patients with mild to moderate acute primary headache crises when compared to paracetamol and placebo. A favorable and tolerable safety profile was also reported.

\section{Acknowledgements}

We thank SENSE Company Brazil for medical writing support in developing drafts of this manuscript.

\section{References}

1. Organization WH. Headache disorders [Internet]. 2016 [cited 2018 Jul 18]. Available from: http:/ / www.who.int/news-room/ fact-sheets/detail/headache-disorders
2. Berk T, Ashina S, Martin V, Newman L, Vij B. Diagnosis and Treatment of Primary Headache Disorders in Older Adults. J Am Geriatr Soc. 2018;66(12):2408-16.

3. Headache Classification Subcommittee of the International Headache Society. The International Classification of Headache Disorders: $2^{\text {nd }}$ edition. Cephalalgia. 2004; 24 Suppl 1(5):9-160.

4. Barambones O, Alkorta P, Gonzalez de Durana JM. The International Classification of Headache Disorders, 3rd edition (beta version). Cephalalgia. 2013; 33(9):629-808.

5. Ahmed F. Headache disorders: differentiating and managing the common subtypes. Br J Pain. 2012; 6(3):124-32.

6. Steiner TJ, Stovner LJ, Vos T, Jensen R, Katsarava Z. Migraine is first cause of disability in under 50s: will health politicians now take notice? J Headache Pain. 2018; 19(1):17-20.

7. Olesen J, Steiner TJ, Bendtsen L, Dodick D, Ducros A, Evers S, et al. The International Classification of Headache Disorders. 3rd ed. 2018. 1-28 p. Headache Classification Committee of the International Headache Society (IHS) The International Classification of Headache Disorders, 3rd edition. Cephalalgia. 2018; 38(1):1-211.

8. Queiroz LP, Silva Junior AA. The prevalence and impact of headache in Brazil. Headache. 2015; 55(S1):32-8.

9. Schramm SH, Moebus S, Lehmann N, Galli U, Obermann M, Bock E, et al. The association between stress and headache: A longitudinal population-based study. Cephalalgia. 2015; 35(10):853-63.

10. James SL, Abate D, Abate KH, Abay SM, Abbafati C, Abbasi $\mathrm{N}$, et al. Global, regional, and national incidence, prevalence, and years lived with disability for 354 diseases and injuries for 195 countries and territories, 1990-2017: a systematic analysis for the Global Burden of Disease Study 2017. Lancet. 2018; 392(10159):1789-858.

11. Saylor D, Steiner TJ. The global burden of headache. Semin Neurol. 2018; 38(2):182-90.

12. Schwedt TJ, Alam A, Reed ML, Fanning KM, Munjal S, Buse DC, et al. Factors associated with acute medication overuse in 
people with migraine: results from the 2017 migraine in America symptoms and treatment (MAST) study. J Headache Pain. 2018; 19(1):1-9.

13. Sociedade Brasileira de Medicina da Família e Comunidade Associação Brasileira de Medicina Física e Reabilitação Academia Brasileira de Neurologia. Cefaleias em adultos na atenção primária à saúde: diagnóstico e tratamento. Projeto Diretrizes. Elaboração Final: 30 de junho de 2009. [São Paulo]: Associação Médica Brasileira; Conselho Federal de Medicna; 2009. 14p.

14. De Souza Carvalho D, Barea LM, Kowacs PA, Fragoso YD. Efficacy and tolerability of combined dipyrone, isometheptene and caffeine in the treatment of mild-to-moderate primary headache episodes. Expert Rev Neurother. 2012; 12(2):159-67.

15. Jasiecka A, Ma lanka T, Jaroszewski JJ. Pharmacological characteristics of metamizole. Pol J Vet Sci. 2014; 17(1):207-14.

16. Willems EW, Valdivia LF, Saxena PR, Villalón CM. Pharmacological profile of the mechanisms involved in the external carotid vascular effects of the antimigraine agent isometheptene in anaesthetised dogs. Naunyn Schmiedebergs Arch Pharmacol. 2001; 364(1):27-32.

17. Tavares C, Sakata RK. Caffeine in the treatment of pain. Rev Bras Anestesiol. 2012; 62(3):387-401.

18. Chagas OFP, Éckeli FD, Bigal ME, Silva MOA da, Speciali JG. Study of the use of analgesics by patients with headache at a specialized outpatient clinic (ACEF). Arq Neuropsiquiatr. 2015; 73(7):586-92.

19. Aicher B, Peil H, Peil B, Diener H. Pain measurement: Visual Analogue Scale (VAS) and Verbal Rating Scale (VRS) in clini- cal trials with OTC analgesics in headache. Cephalalgia. 2011; 32(3):185-97.

20. Brasil. Ministério da Saúde. Agencia Nacional de Vigilância Sanitária. (ANVISA). Resolução RDC n ${ }^{\circ} 36$, de 27 de Junho de 2012. Altera a RDC no. 39, de 05 de junho de 2008 e dá outras providências. [Internet]. [citado 2019 Dez 6]. Disponível em: http:/ /bvsms.saude.gov.br/bvs/saudelegis/anvisa/2012/ rdc0036_27_06_2012.html

21. Arrais PSD, Fernandes MEP, Pizzol T da SD, Ramos LR, Mengue SS, Luiza VL, et al. Prevalence of self-medication in Brazil and associated factors. Rev Saude Publica. 2016; 50(suppl 2):13s.

22. Krymchantowski AV. Acute treatment of migraine. breaking the paradigm of monotherapy. BMC Neurol. 2004; 4:4.

23. Newman LC. Why Triptan treatment can fail: focus on gastrointestinal manifestations of migraine. Headache. 2013; 53(suppl.1):11-6.

24. Silberstein SD, Young WB. Safety and efficacy of ergotamine tartrate and dihydroergotamine in the treatment of migraine and status migrainosus. Working Panel of the Headache and Facial Pain Section of the American Academy of Neurology. Neurology. 1995; 45(3 Pt 1):577-84.

25. Frey GH. The role of placebo response in clinical headache evaluations. Headache. 1961;1:31-8.

Trabalho recebido: 04/09/2019

Trabalho aprovado: 09/12/2019

Trabalho publicado: 09/12/2019 